\title{
SIMULADORES E TECNOLOGIAS ASSISTIVAS PARA DALTONISMO
}

\section{SIMULATORS AND ASSISTIVE TECHNOLOGY FOR COLOR BLINDNESS}

\author{
Gilmar Vitor da Silva Andrade ${ }^{1}$, Graduando \\ Joseh Augusto Dantas Salgado Pinto ${ }^{2}$, Graduando \\ Bruno Santana da Silva ${ }^{3}$, D.Sc. \\ (1) Universidade Federal do Rio Grande do Norte \\ e-mail: gilmar-andrade@outlook.com \\ (2) Universidade Federal do Rio Grande do Norte \\ e-mail: josehaugustodsp@gmail.com \\ (3) Universidade Federal do Rio Grande do Norte \\ e-mail: bruno@imd.ufrn.br
}

daltonismo, simulador, ferramenta assistiva, acessibilidade

\begin{abstract}
A percepção de cores afeta como as pessoas interagem com o mundo, em particular se as cores tiverem significados associados. Simuladores e ferramentas assistivas têm sido desenvolvidos para promover acessibilidade a daltônicos. Este trabalho compara simuladores como suporte para não-daltônicos projetarem e avaliarem interfaces de sistemas computacionais para daltônicos, e compara tecnologias assistivas computacionais como apoio às atividades cotidianas de daltônicos. O designer pode usar alguns simuladores para facilitar a análise estática e outros para a análise dinâmica da interface, durante avaliações formativas ou somativas. Ele também podem usar tecnologias assistivas para prever como um daltônico poderia interagir com sistemas computacionais com este apoio.
\end{abstract}

\section{color blindness, simulator, assistive tool, accessibility}

How people perceive colors can affect their interaction with the world, especially if colors have associated meanings. Simulators and assistive tools have been developed to promote accessibility for color blinds. This work compares how simulators can support not color blinds design and evaluate interfaces of computational systems for color blinds, and compares how assistive computational tools can support color blinds perform every day activities. Designers can use some simulators to facilitate static analysis of user interface and others to dynamic analysis. They also can use assistive tools to preview how a colorblind could interact with systems with this support.

\section{Introdução}

As pessoas empregam seus sentidos e movimentos para interagir com o mundo ao seu redor, seja para percebê-lo, interpretá-lo ou atuar sobre ele. Dos sentidos responsáveis pela percepção, a visão costuma ser o mais utilizado para estarmos cientes do que acontece ao nosso redor. Quando a luz incide sobre os olhos, as primeiras diferenciações que costumamos fazer envolvem identificar

\section{Realização:
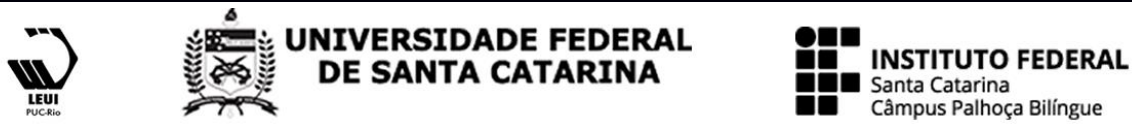


\section{$16^{\circ}$ \\ ERGODESIGN USIHC CINAHPA}

presença e ausência de luz, seguidas da distinção de luzes por cores [Farina et al., 2006]. Após a identificação de cores, nosso cérebro é capaz de associá-las a certos significados.

Algumas pessoas têm dificuldades em identificar cores, por isso são popularmente chamados de daltônicos [Bruni e Cruz, 2006]. Entre 6\% e 10\% dos homens e $0,4 \%$ a $0,7 \%$ das mulheres são daltônicos no mundo [Gordon, 1998]. Apesar de não aparentar, daltônicos relatam dificuldades em diferentes fases da vida [Melo et al., 2014].

Numa sociedade da informação cada vez mais digital e conectada, as pessoas produzem e consomem um grande volume de informação representada em sistemas computacionais. Muitos serviços são oferecidos exclusivamente pelo meio digital; inclusive serviços oferecidos pelo governo, como matrícula em escolas e inscrição em seleções (ENEM) e concursos, por exemplo. Quem projeta e avalia a interface com usuário desses sistemas deveria considerar que uma parcela considerável da população mundial não consegue identificar determinadas cores. É relevante que os sistemas sejam acessíveis para os daltônicos.

As diferentes capacidades de visualizar cores [Farina et al., 2006] são um grande desafio para o projeto e avaliação da interface com usuário. Uma pessoa não daltônica percebe o mundo de um modo diferente de quem é daltônico. Mesmo daltônicos podem perceber o mundo de modos distintos, pois existem diferentes tipos de daltonismo. Diante disso, como um designer pode projetar uma interface adequada para uma realidade que ele não conhece? Como ele pode julgar se determinada interface é boa para uma pessoa diferente dele?

Existem várias ferramentas digitais desenvolvidas para lidar com o daltonismo. Neste trabalho, apresentamos uma revisão de algumas ferramentas, destacando seu possível uso por pessoas não daltônicas durante o processo de design de interface para daltônicos. Por fim, também analisamos como algumas ferramentas podem auxiliar daltônicos a realizarem suas atividades cotidianas, incluindo o uso de sistemas. $16^{\circ}$ Ergodesign - Congresso Internacional de Ergonomia e Usabilidade de Interfaces Humano Tecnológica: Produto, Informações Ambientes Construídos e Transporte

$16^{\circ}$ USIHC - Congresso Internacional de Ergonomia e Usabilidade de Interfaces Humano Computador

CINAHPA | 2017 - Congresso Internacional de Ambientes Hipermídia para Aprendizagem.

\section{Daltonismo}

Quando a luz incide sobre o mundo ao nosso redor, ele reflete essa luz que chega aos nossos olhos. Estes órgãos são a porta de entrada de um dos principais estímulos externos para percebermos o que nos cerca. A nossa visão começa nos olhos com a captação da luz refletida e geração de estímulos nervosos para nosso cérebro. Cabe ao cérebro dar sentido aos estímulos luminosos recebidos para compreendermos o que estamos vendo [Farina et al., 2006].

A luz é uma energia composta por ondas de diferentes comprimentos [Silva e Martins, 1996]. Nossos olhos possuem células receptoras capazes de diferenciar a intensidade e o comprimento de onda das luzes captadas. A intensidade ativa os bastonetes; e o comprimento estimula os cones.

A percepção da cor é viável quando os cones são estimulados por luzes de comprimentos de onda diferentes. [Farina et al., 2006] discute algumas teorias que explicam a percepção de cor. Uma das mais aceitas atualmente é a existência de cones capazes de identificar três cores primárias: vermelho, verde e azul. Combinações de percepção dessas três cores primárias nos olhos permitem ao cérebro interpretar uma variada gama de cores naquilo que enxergamos.

Quando os cones não são capazes de perceber ou diferenciar estímulos de luzes com comprimentos de onda correspondentes ao vermelho, verde ou azul, as pessoas têm dificuldades de enxergar determinadas cores. O mau funcionamento dos cones geralmente está associado a uma condição genética conhecida como daltonismo [Bruni e Cruz, 2006; Gordon, 1998]. Existem vários tipos de daltonismo, normalmente classificados de acordo com a capacidade de percepção de cores.

Se os cones não forem capazes de identificar nenhum comprimento de onda, a pessoa não consegue ver cores, ou seja, vê o mundo apenas em preto, branco e tons de cinza. Essa condição rara é conhecida como acromacia ou acromatismo.

Casos mais comuns de daltonismo limitam a 


\section{$16^{\circ}$ \\ ERGODESIGN USIHC CINAHPA}

visualização de uma das cores primárias pelo mau funcionamento dos cones (ou ausência deles). A protanomalia representa uma dificuldade de percepção do vermelho. A deuteranomalia indica a dificuldade de percepção do verde. Já a tritonomalia apresenta uma dificuldade de percepção do azul.

Uma parte considerável da população mundial (até $8 \%$ ) possui algum tipo de daltonismo. A condição física dos daltônicos costuma passar despercebida, pois não apresenta nenhuma diferença física visível para os outros. Mesmo assim, os daltônicos enfrentam dificuldades ao longo da vida [Melo et al., 2014]. Eles têm problemas para lidar com o material didático e em desempenhar atividades educacionais desde o ensino fundamental até a universidade. Sentem dificuldades para interpretar sinais de trânsito ou luzes indicativas. Não consideram a possibilidade de desempenhar determinadas profissões. Além de passar por situações constrangedoras em que outras pessoas se divertem com a sua condição. Eles não podem ser desprezados na sociedade, principalmente na sociedade da informação que cada vez mais utiliza cores para interagir.

\section{Acessibilidade}

Nas últimas décadas, a sociedade começou a se preocupar em oferecer melhores condições para pessoas com necessidades especiais participarem de forma autônoma e plena do convívio social. Em 2009, o governo brasileiro promulgou a convenção internacional da ONU sobre os direitos das pessoas com deficiência [Brasil, 2009]. Diversas iniciativas começaram a ser desenvolvidas para favorecer a acessibilidade, ou seja, para "assegurar às pessoas com deficiência o acesso, em igualdade de oportunidades com as demais pessoas, ao meio físico, ao transporte, à informação e comunicação, inclusive aos sistemas e tecnologias da informação e comunicação, bem como a outros serviços e instalações abertos ao público ou de uso público, tanto na zona urbana como na rural" [Brasil, 2009].

No que diz respeito ao uso de sistemas computacionais, acessibilidade se refere à capacidade de o usuário acessar o sistema para $16^{\circ}$ Ergodesign - Congresso Internacional de Ergonomia e Usabilidade de Interfaces Humano Tecnológica: Produto, Informações Ambientes Construídos e Transporte

$16^{\circ}$ USIHC - Congresso Internacional de Ergonomia e Usabilidade de Interfaces Humano Computador

CINAHPA | 2017 - Congresso Internacional de Ambientes Hipermídia para Aprendizagem.

interagir com ele, sem que a interface imponha obstáculos [Melo e Baranauskas, 2006; Barbosa e Silva, 2010; Rogers et al., 2013]. O usuário precisa ser capaz de agir sobre a interface do sistema através de algum dispositivo de entrada (mouse, teclado, câmera, microfone, etc.) e ser capaz de perceber os resultados através dos dispositivos de saída (alto-falantes, tela/monitor, etc.).

\subsection{Barreiras de Acessibilidade para Daltônicos}

A comunicação visual vem ganhando cada vez mais relevância com a crescente diversidade de meios analógicos e digitais para se registrar e trocar informações. A cor recebe destaque por se tratar de um recurso de comunicação importante [Farina et al., 2006].

A cor tem sido bastante utilizada para representar informações em interfaces com usuário de sistemas computacionais. É muito comum a cor representar algum estado do sistema (e.g. aviso, erro, confirmação) ou de alguma variável (e.g. bom, regular e ruim); representar diferenças num mapa ou gráfico; ou mesmo representar ideias através de uma imagem colorida.

Quando uma informação é representada por cores, os daltônicos podem não ser capazes de percebê-la. Neste caso, a representação da informação na interface torna-se uma barreira de acesso ao daltônico, dificultando ou impedindo o seu uso.

Vários estudos têm sido realizados sobre a interação de daltônicos com artefatos coloridos: mapas [Jenny e Kelso, 2007; Maia e Spinillo, 2013], sinalização viária [Soares, 2009] e roupas [Gomes et al., 2016], por exemplo. Existe inclusive uma proposta de símbolos reconhecíveis por forma para representar cores para daltônicos [Neiva e Guedes, 2009]. No mundo digital, as primeiras iniciativas para facilitar a interação de daltônicos têm buscado desenvolver ferramentas que simulam o daltonismo e ferramentas assistivas que auxiliem o daltônico a lidar com cores.

Este trabalho faz uma análise de algumas ferramentas existentes com o objetivo de instrumentar o designer não daltônico para 


\section{$16^{\circ}$ \\ ERGODESIGN USIHC CINAHPA}

perceber e lidar com as necessidades do usuário daltônico durante o uso de sistemas computacionais. Essas ferramentas foram encontradas através de pesquisa no Google, lojas de aplicativos móveis e de extensões de navegadores web, utilizando os termos "simulador", "daltonismo" e "tecnologia assistiva". Não tivemos a intenção de ser exaustivos, apenas selecionamos algumas ferramentas de acesso gratuito para identificar tipos de ferramentas e analisar sua utilidade durante o design de interface.

\section{Simuladores de Daltonismo Como Apoio ao Design de Sistemas Computacionais}

Para quem enxerga um espectro maior de cores, é muito difícil imaginar como seria perceber o mundo com uma restrição importante de cores. $\mathrm{Na}$ maioria das vezes este é um exercício mental inviável de ser feito. Para piorar, existem vários tipos de daltonismo. Essa falta de percepção do designer não daltônico inviabiliza seu julgamento de valor sobre uma solução de interface sendo concebida para daltônicos. Ele tem dificuldades de se colocar no lugar do usuário para criticar sua própria solução e comparar alternativas de solução. Desse modo, um designer não daltônico pode ter dificuldade para realizar avaliações formativas e somativas [Rogers et al, 2013] quando considera daltônicos como usuários.

Simuladores de daltonismo podem ser uma ferramenta bastante útil para ajudar o designer a superar sua dificuldade de enxergar a interface como um usuário daltônico faria. Alguns trabalhos anteriores apresentam revisões de algoritmos utilizados para construir tais ferramentas [Ferraz, 2011]. Nosso objetivo aqui é diferente.

Comparamos alguns simuladores de acesso gratuito para identificar tipos (ou classes), e analisamos como esses tipos poderiam ser utilizados durante o processo de design.

Identificamos quatro tipos de simuladores: os que aplicam filtros em arquivos de imagens, que aplicam filtros na tela do computador, que alteram sites web e os que aplicam filtros na câmera de dispositivos móveis. $16^{\circ}$ Ergodesign - Congresso Internacional de Ergonomia e Usabilidade de Interfaces Humano Tecnológica: Produto, Informações Ambientes Construídos e Transporte

$16^{\circ}$ USIHC - Congresso Internacional de Ergonomia e Usabilidade de Interfaces Humano Computador

CINAHPA | 2017 - Congresso Internacional de Ambientes Hipermídia para Aprendizagem.

\subsection{Simuladores de Imagem}

Alguns simuladores de daltonismo são capazes de processar uma imagem com todo o espectro de cores visíveis a um designer não daltônico e entregar outra imagem contendo uma simulação do que estaria sendo visto por daltônicos dos três tipos: protanomalia, deuteranomalia e tritonomalia.

[Oliveira et al., 2014] compara os filtros de imagem Web-Safe Palette, Chromatic Vision Simulator e Vischeck, analisando apenas a qualidade da imagem gerada. O primeiro é um software pago, por isso ficou fora do nosso estudo. Como na comparação de [Oliveira et al., 2014], escolhemos uma imagem que abrange muitas cores do espectro visível (Figura 1). Utilizamos o Colour Blindness Simulator (http://www.etre.com/tools/ colourblindsimulator/), Chromatic Vision Simulator (http://asada.tukusi.ne.jp/webCVS/) e Vischeck (http://www.vischeck.com/vischeck/) para gerar imagens que simulam três tipos de daltonismo. Os resultados são apresentados nas Figuras 2, 3 e 4. É possível perceber diferenças sutis entre as simulações desses sites.

O Colour Blindness Simulator (Figura 2) teve problemas para realizar uma transição suave entre cores em todos os tipos de daltonismo. Com destaque para a transição entre verde e azul claro que sofreu com uma leve ausência de cor (tons de preto) na deuteranomalia e para as transições abruptas em torno do azul escuro na tritonomia. É possível perceber borrões neste último tipo.

O Chromatic Vision Simulator (Figura 3) teve problemas para realizar uma transição suave entre cores em todos os tipos de daltonismo, com destaque nas transições em torno do vermelho e rosa.

Por fim, no Vischeck (Figura 4) percebem-se poucos problemas de transição entre cores em todas as simulações, principalmente em torno do vermelho, rosa e azul escuro.

Não foram observados borrões nos dois últimos simuladores, como ocorreu em [Oliveira et al., 2014]. Talvez porque os sistemas tenham sido 


\section{$16^{\circ}$ \\ ERGODESIGN USIHC CINAHPA}

aprimorados ou a imagem utilizada aqui seja mais linear do que circular. Dos três simuladores, o $16^{\circ}$ Ergodesign - Congresso Internacional de Ergonomia e Usabilidade de Interfaces Humano Tecnológica: Produto, Informações Ambientes Construídos e Transporte

$16^{\circ}$ USIHC - Congresso Internacional de Ergonomia e Usabilidade de Interfaces Humano Computador

CINAHPA | 2017 - Congresso Internacional de Ambientes Hipermídia para Aprendizagem.

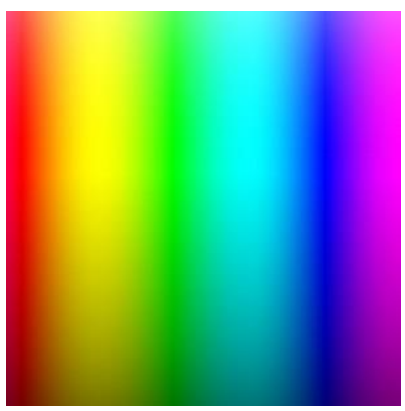

Vischeck apresentou melhor fidelidade na conversão das cores e transição entre elas.

Figura 1. Imagem representando as cores do espectro visível de um usuário normal (fonte https://manuelaroundtheworld.files.wordpress.com/2015/01/e4b883e889b2.jpg).
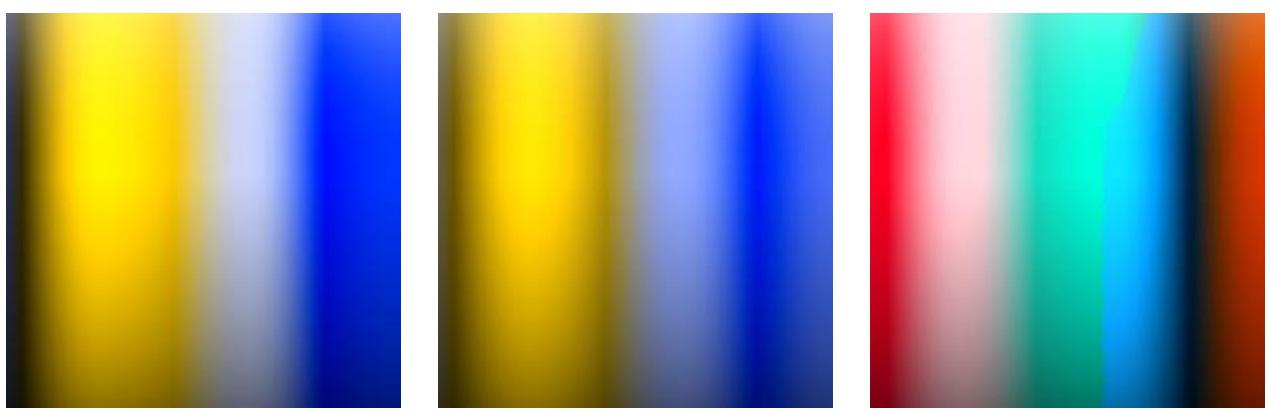

Figura 2. Simulação de protanomalia (esq.), deuteranomalia, tritonomalia (dir.) no Colour Blindness Simulator.
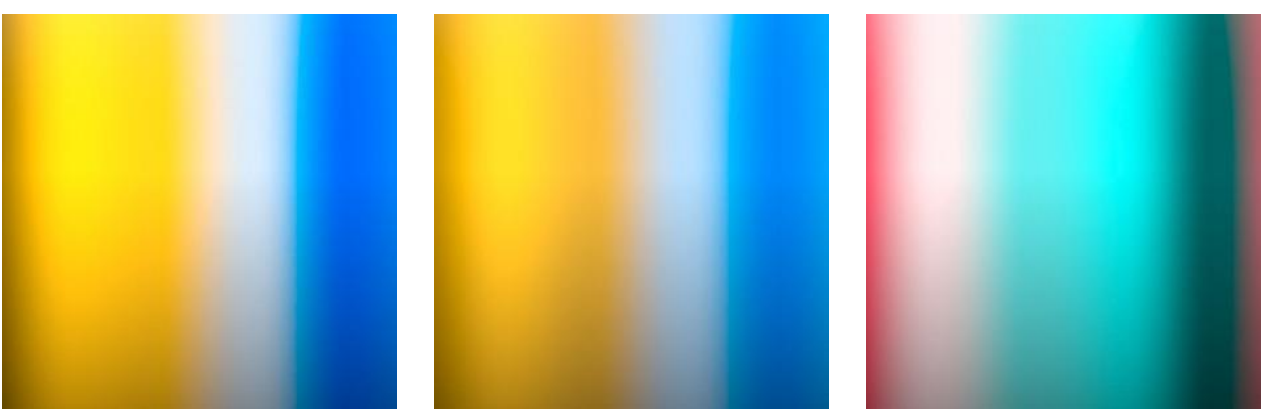

Figura 3. Simulação de protanomalia (esq.), deuteranomalia, tritonomalia (dir.) no Chromatic Vision Simulator.
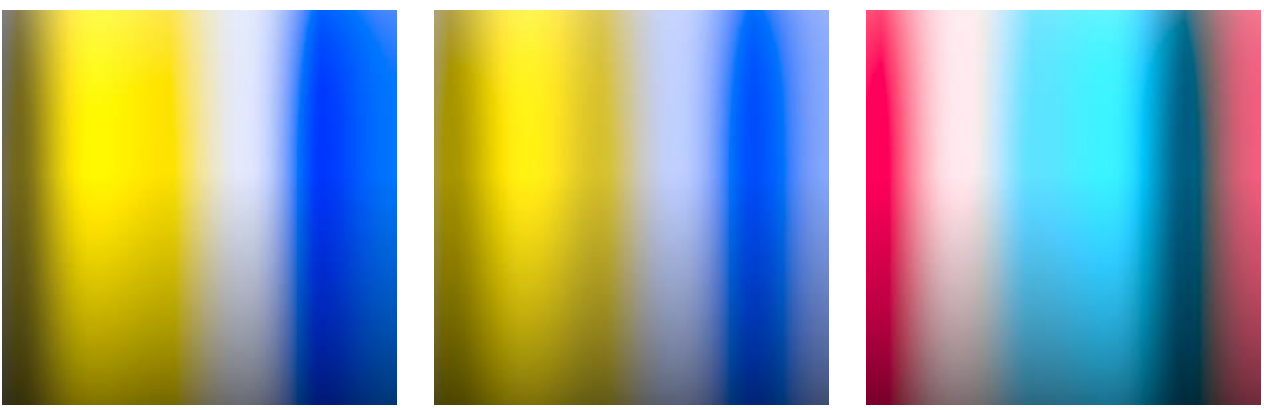

Figura 4. Simulação de protanomalia (esq.), deuteranomalia, tritonomalia (dir.) no Vischeck. 


\section{$16^{\circ}$ \\ ERGODESIGN USIHC CINAHPA}

Cada imagem simulada foi obtida através do envio do arquivo da Figura 1 para os respectivos sites, selecionando a opção do tipo de daltonismo desejado. No primeiro e terceiro simulador, foram necessários seis envios desta imagem para o obtermos esses resultados. Apenas no Chromatic Vision Simulator foi necessário somente um envio.

Se o designer quiser perceber como sua interface seria enxergada por um daltônico, ele teria que enviar para um site todos os arquivos de imagem que a representam. Todavia, nem sempre o designer estaria disposto a fazer isso, seja pelo esforço envolvido ou por questões de sigilo. Como funcionam com arquivos, simuladores de daltonismo por imagem permitem que o designer analise a interface com usuário apenas de maneira estática, sem poder explorá-la sob o dinamismo do processo de interação.

\subsection{Simuladores de Tela}

Os simuladores de tela são capazes de aplicar filtros que simulam o daltonismo sobre tudo o que está sendo exibido na tela do computador. O único simulador de tela encontrado foi o Color Oracle (http://colororacle.org/). Ele é gratuito e funciona em Windows, Mac e Linux.

O Color Oracle aplica um filtro de cor sobre o que aparece em toda tela do computador para simular os três tipos mais comuns de daltonismo. Ele permite ao designer enxergar tudo o que aparece na tela de modo similar a um daltônico, sem a necessidade de salvar em arquivo uma imagem da tela e enviar para um site. Isso representa uma vantagem significativa em relação aos simuladores de imagem em termos de eficiência, uso de conexão com a internet e de sigilo.

O botão do Color Oracle fica na barra de tarefas. O designer ativa a simulação do daltonismo clicando nele, e desativa-a clicando em qualquer outro lugar da tela. Apesar de este ser um modo fácil e eficiente para entrar e sair da simulação, ele limita o que é possível fazer durante. O Color Oracle permite apenas analisar a interface de forma estática, mas inviabiliza a interação com a interface durante a simulação, do mesmo modo que $16^{\circ}$ Ergodesign - Congresso Internacional de Ergonomia e Usabilidade de Interfaces Humano Tecnológica: Produto, Informações Ambientes Construídos e Transporte

$16^{\circ}$ USIHC - Congresso Internacional de Ergonomia e Usabilidade de Interfaces Humano Computador

CINAHPA | 2017 - Congresso Internacional de Ambientes Hipermídia para Aprendizagem.

os simuladores de imagem. [Oliveira et al., 2014] também analisou a qualidade da simulação do Color Oracle, que foi considerada a melhor dentre os quatro simuladores comparados.

\subsection{Simulador de Sites Web}

Alguns simuladores abrangem apenas sites web.

Parte deles processa a simulação no próprio navegador web através de extensões do navegador. Outra parte realiza o processamento da simulação em outro site web que entrega o resultado para o navegador do usuário.

Foram analisadas quatro extensões para o navegador Chrome: Spectrum, NoCoffee Vision Simulator, Colorblinding, e I want to see like the colour blind. Todas simulam os três tipos mais comuns de daltonismo, são de acesso gratuito e funcionam em Windows, Mac e Linux.

A maior vantagem de um simulador de sites ser extensão de um navegador web é a possibilidade de processar localmente toda a página para a simulação: imagens, HTML e CSS. As cores de texto, imagens e plano de fundo podem ser modificadas rapidamente pela extensão do navegador web para simular os três tipos de daltonismo. Sendo assim, o designer tem a possibilidade de enxergar todo o site como se fosse um daltônico; não apenas de forma estática analisando a imagem de cada página, mas também de forma dinâmica interagindo com o site durante a simulação, como um usuário daltônico faria. A maior limitação das extensões de navegadores web é a incapacidade de abranger toda a tela do computador, como o Color Oracle faz.

Os resultados da simulação de daltonismo nas quatro extensões analisadas foram muito similares. Com destaque para o NoCoffee Vision Simulator, por simular também outras alterações visuais, tais como: baixo contraste, fantasmas, borrão e neve.

Alguns simuladores de sites são outros sites web, que recebem um endereço de internet (URL), copiam o conteúdo do site, alteram as cores e, por fim, entregam ao navegador web o site desejado pelo designer com a simulação de daltonismo. $\mathrm{O}$ 


\section{$16^{\circ}$ \\ ERGODESIGN USIHC CINAHPA}

ColorFilter (http://colorfilter.wickline.org/) foi o único simulador desse tipo que encontramos em funcionamento. Ele permite alternar a simulação entre os três tipos de daltonismo.

Percebemos que o ColorFilter tem funcionamento limitado na prática. Ele altera satisfatoriamente as cores dos textos, de fundo e de imagens em alguns sites web. Em outros sites, ele nem sempre é capaz de alterar todos os elementos. As áreas que o simulador não foi capaz de processar são exibidas em cinza. Se o site possui uma estrutura mais complexa (com utilização de javascript), o layout pode ser totalmente desconfigurado, tornando a navegação inviável. Nos piores casos, o resultado final da simulação foi apenas uma página em branco. Ao clicar em um link no site com a simulação de daltonismo ativada, a simulação deixa de funcionar na nova parte do site. Então, apesar de poder ser uma opção interessante por não exigir instalação de extensão, o ColorFilter não oferece ao designer uma simulação contínua durante a interação com o site.

Foi mais rápido e eficaz trocar o tipo de daltonismo em simuladores que são extensão do navegador web, do que utilizando um site web como o ColorFilter para realizar a simulação. Isso provavelmente ocorre porque depois que uma página web foi carregada para a primeira simulação, todos os elementos necessários não precisaram ser copiados novamente da internet. Tudo que a extensão do navegador precisava para simular o daltonismo já se encontrava localmente.

\subsection{Simulador via Câmera de Dispositivo Móvel}

A câmera de dispositivos móveis também foi explorada por simuladores de daltonismo.

Analisamos dois aplicativos gratuitos para Android que simulam os três tipos de daltonismo a partir de imagens captadas em tempo real pela câmera:

Chromatic Vision Simulator e Daltonizer.

O Chromatic Vision Simulator divide a tela do dispositivo em um, dois ou quatro compartimentos. Eles apresentam a imagem real capturada pela câmera ao lado da simulação dos tipos de daltonismo (esquerda na Figura 5), facilitando a $16^{\circ}$ Ergodesign - Congresso Internacional de Ergonomia e Usabilidade de Interfaces Humano Tecnológica: Produto, Informações Ambientes Construídos e Transporte

$16^{\circ}$ USIHC - Congresso Internacional de Ergonomia e Usabilidade de Interfaces Humano Computador

CINAHPA | 2017 - Congresso Internacional de Ambientes Hipermídia para Aprendizagem.

comparação do que os daltônicos e não daltônicos estariam enxergando. Permite configurar a qualidade da visualização; porém, quanto maior a qualidade da imagem, mais lento se torna a simulação do daltonismo. Ele também permite alterar o zoom na imagem da câmera e capturar uma imagem da tela comparando as visualizações.
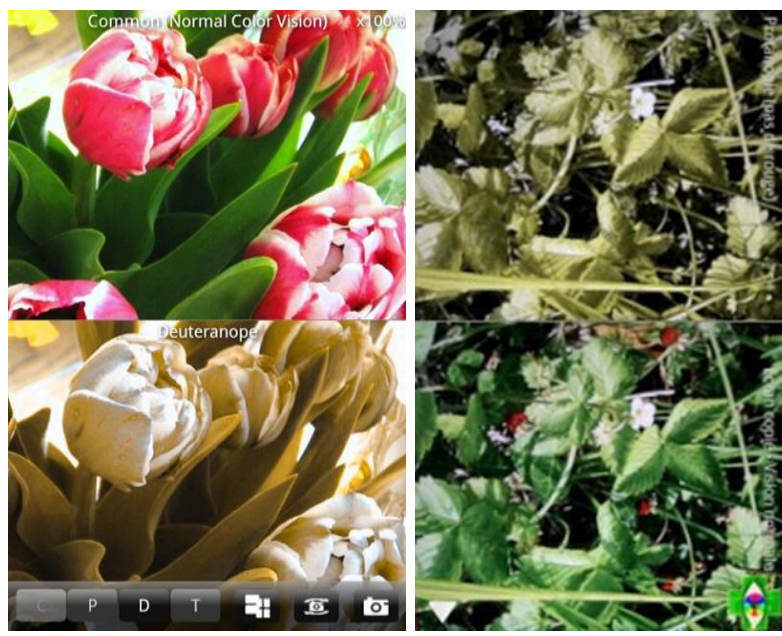

Figura 5. Aplicativos Chromatic Vision Simulator (esquerda) e Daltonizer (direita) (fonte: Play Store).

O Daltonizer permite dividir a tela do dispositivo em até duas partes, metade com a imagem original e outra metade com a simulação de um tipo de daltonismo (direita na Figura 5). Ele permite congelar a imagem, ligar e desligar o flash da câmera, e alterar a qualidade da simulação. Porém, a qualidade da imagem é inversamente proporcional à velocidade da simulação.

O designer pode precisar analisar a acessibilidade para daltônicos de interface cuja representação esteja somente em meio não digital ou em dispositivo fora do seu controle. Por exemplo, ele pode precisar analisar interfaces representadas em papel, projetadas numa superfície (por uma apresentação de slides), ou mesmo em computadores e dispositivos de outras pessoas que ele não pode utilizar. Nesses casos, os três primeiros tipos de simuladores discutidos aqui não seriam úteis. Caso o designer tivesse um simulador de daltonismo instalado no seu dispositivo móvel, ele poderia ter uma boa noção de como essas interfaces seriam percebidas por um daltônico. 
$16^{\circ}$ Ergodesign - Congresso Internacional de Ergonomia e Usabilidade de Interfaces Humano Tecnológica: Produto, Informações Ambientes Construídos e Transporte

$16^{\circ}$ USIHC - Congresso Internacional de Ergonomia e Usabilidade de Interfaces Humano Computador

CINAHPA | 2017 - Congresso Internacional de Ambientes Hipermídia para Aprendizagem.

\begin{tabular}{|c|c|c|c|c|}
\hline Simulador & Plataforma & Qualidade & Restrições & Diferencial \\
\hline \multicolumn{5}{|c|}{ Simuladores de imagem (estático - interface) } \\
\hline $\begin{array}{l}\frac{\text { Colour }}{\text { Blindness }} \\
\underline{\text { Simulator }}\end{array}$ & sistema web & Ruim & $\begin{array}{l}\text { Arquivo JPEG de até } 100 \mathrm{~KB} \text {. Resultado } \\
\text { em baixa resolução. Apenas um tipo de } \\
\text { daltonismo por envio de arquivo. }\end{array}$ & \\
\hline $\begin{array}{l}\text { Chromatic } \\
\underline{\text { Vision }} \\
\underline{\text { Simulator }}\end{array}$ & sistema web & Regular & & $\begin{array}{l}\text { Facilita a comparação lado a lado de } \\
\text { simulações dos três tipos de daltonismo } \\
\text { com apenas um envio de imagem. }\end{array}$ \\
\hline Vischeck & sistema web & Boa & $\begin{array}{l}\text { Apenas um tipo de daltonismo por envio } \\
\text { de arquivo. }\end{array}$ & $\begin{array}{l}\text { Aceita vários formatos e tamanhos de } \\
\text { arquivo. }\end{array}$ \\
\hline \multicolumn{5}{|c|}{ Simuladores de tela (estático - interface) } \\
\hline$\underline{\text { Color Oracle }}$ & sistema desktop & Boa & $\begin{array}{l}\text { Não é possível interagir com o sistema } \\
\text { durante a simulação }\end{array}$ & Altera todas as cores. \\
\hline \multicolumn{5}{|c|}{ Simulador de sites web (dinâmico - interação e interface) } \\
\hline$\underline{\text { Spectrum }}$ & $\begin{array}{l}\text { complemento de } \\
\text { navegador }\end{array}$ & Boa & Funciona apenas no Google Chrome & $\begin{array}{l}\text { Altera todas as cores. É possível interagir } \\
\text { durante a simulação. }\end{array}$ \\
\hline $\begin{array}{l}\frac{\text { NoCoffee }}{\text { Vision }} \\
\underline{\text { Simulator }}\end{array}$ & $\begin{array}{l}\text { complemento de } \\
\text { navegador }\end{array}$ & Boa & Funciona apenas no Google Chrome & $\begin{array}{l}\text { Altera todas as cores. É possível interagir } \\
\text { durante a simulação. } \\
\text { Também simula outras alterações visuais. }\end{array}$ \\
\hline$\underline{\text { Color }}$ & $\begin{array}{l}\text { complemento de } \\
\text { navegador }\end{array}$ & Boa & Funciona apenas no Google Chrome & $\begin{array}{l}\text { Altera todas as cores. É possível interagir } \\
\text { durante a simulação. }\end{array}$ \\
\hline $\begin{array}{l}\frac{\text { I want to see }}{\text { like the colour }} \\
\underline{\text { blind }}\end{array}$ & $\begin{array}{l}\text { complemento de } \\
\text { navegador }\end{array}$ & Boa & Funciona apenas no Google Chrome & $\begin{array}{l}\text { Altera todas as cores. É possível interagir } \\
\text { durante a simulação. }\end{array}$ \\
\hline$\underline{\text { ColorFilter }}$ & sistema web & Ruim & $\begin{array}{l}\text { Desconfigura layout da página. } \\
\text { Simulação desaparece ao mudar página. }\end{array}$ & \\
\hline \multicolumn{5}{|c|}{ Simulador via câmera de dispositivos míveis (dinâmico - interação) } \\
\hline $\begin{array}{l}\text { Chromatic } \\
\underline{\text { Vision }} \\
\underline{\text { Simulator }}\end{array}$ & aplicativo móvel & Boa & $\begin{array}{l}\text { Pode apresentar atraso na simulação em } \\
\text { alta qualidade. }\end{array}$ & $\begin{array}{l}\text { Divide a tela em até } 4 \text { compartimentos e } \\
\text { compara todos os tipos de daltonismo. } \\
\text { Permite zoom e salva imagem da tela. }\end{array}$ \\
\hline$\underline{\text { Daltonizer }}$ & aplicativo móvel & Boa & $\begin{array}{l}\text { Pode apresentar atraso na simulação em } \\
\text { alta qualidade. Não compara os tipos de } \\
\text { daltonismo. }\end{array}$ & $\begin{array}{l}\text { Divide a tela em } 2 \text { compartimentos. } \\
\text { Permite congelar imagem e ligar/desligar } \\
\text { flash da câmera. }\end{array}$ \\
\hline
\end{tabular}

Tabela 1. Comparação de simuladores para daltonismo.

\subsection{Comparação de Simuladores}

Os diferentes tipos de simuladores de daltonismo podem auxiliar o designer não daltônico durante a avaliação formativa e somativa através da inspeção de interfaces [Barbosa e Silva, 2010] para daltônicos; ou mesmo para apoiar reflexões críticas do designer sob suas ideias de solução. A Tabela 1 apresenta uma visão geral das principais características dos simuladores analisados.

Os simuladores de imagem e tela são adequados para inspecionar a interface sem considerar a interação, dado que são capazes de simular o daltonismo em imagens estáticas. Os simuladores de sites web e via câmera de dispositivos móveis permitem o designer inspecionar a interface 


\section{$16^{\circ}$ \\ ERGODESIGN USIHC CINAHPA}

enquanto interage com ela, não desprezando a experiência dinâmica da interação que os daltônicos teriam.

Se o designer não puder instalar um simulador, deveria considerar o uso de simuladores de imagens (principalmente o Vischeck pela qualidade), simuladores via dispositivo móvel (principalmente o Chromatic Vision Simulator, pela comparação dos daltonismos), ou o

ColorFilter, único simulador de site que não requer nenhuma instalação.

Se o designer puder instalar um simulador, deveria considerar o Color Oracle para inspeção de softwares desktops (ou qualquer outra coisa na tela do computador) e o NoCoffee Vision Simulator para inspeção de sites web (já que permite considerar também outras dificuldades visuais).

\section{Tecnologias Assistivas para Daltônicos}

Quando o designer toma todo o cuidado necessário para produzir uma interface acessível, nem sempre ele é capaz de entregar uma única solução para pessoas com capacidades muito distintas. Por exemplo, quando um designer concebe um site para pessoas cegas e com visão normal, ele costuma utilizar imagens com conteúdo para pessoas que conseguem vê-las, mas também precisa pensar numa forma alternativa de utilizar o sistema com apoio de uma tecnologia assistiva, como um leitor de tela, por exemplo. O designer precisa conhecer tecnologias assistivas para ser capaz de conceber interfaces que em conjunto com essas tecnologias possam ser acessíveis aos usuários que necessitem desse apoio extra.

Que tecnologias assistivas existem para auxiliar a vida dos daltônicos? Como elas poderiam ser utilizadas durante o uso de sistemas computacionais? Identificamos algumas tecnologias assistivas para daltônicos: site web, aplicativos móveis e alterações de CSS.

Geralmente elas envolvem identificação de cores ou recoloração de imagens com cores visíveis aos daltônicos [Ribeiro e Gomes, 2010]. $16^{\circ}$ Ergodesign - Congresso Internacional de Ergonomia e Usabilidade de Interfaces Humano Tecnológica: Produto, Informações Ambientes Construídos e Transporte

$16^{\circ}$ USIHC - Congresso Internacional de Ergonomia e Usabilidade de Interfaces Humano Computador

CINAHPA | 2017 - Congresso Internacional de Ambientes Hipermídia para Aprendizagem.

O Colblindor (http://www.color-blindness.com/ color-name-hue/ ) é um sistema web gratuito que informa o nome da cor a partir do código RGB fornecido pelo usuário (esquerda da Figura 6). Isoladamente, este site não auxilia muito o daltônico. Seria necessário usar em conjunto outra ferramenta como a extensão ColorZilla para Firefox ou Chrome. Esta extensão funciona como um "conta-gotas" que identifica o valor RGB de uma determinada área da página clicada pelo mouse. Pela complexidade, é provável que poucos daltônicos consigam utilizar essas ferramentas em conjunto com destreza.
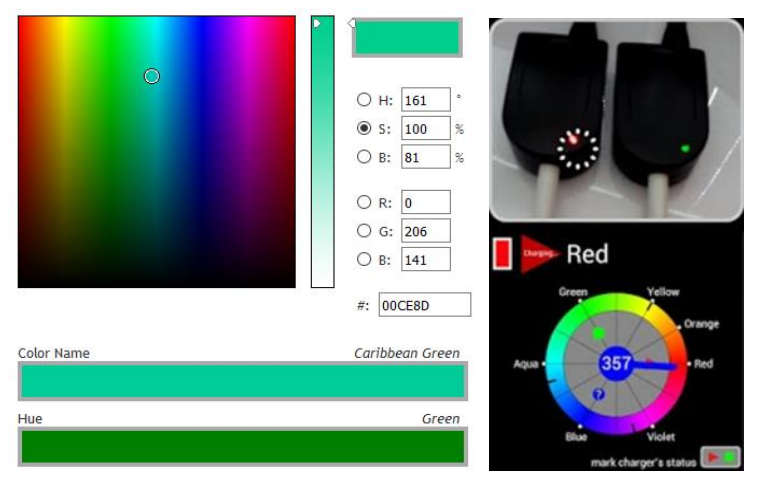

Figura 6. Parte principal do Colblindor (esquerda, fonte site da ferramenta) e do LedScope (direita, fonte Play Store).

O LedScope é um aplicativo móvel que inspeciona cores. Ele utiliza a câmera do dispositivo para identificar os valores RGB da área marcada pelo círculo pontilhado e faz um cálculo de mediana sobre esses valores. O resultado da detecção é representado na forma de texto (red), valor digital e um ponteiro na roda de cores (direita da Figura $6)$.

A área da imagem a ser analisada pode ser alterada, movendo-se a posição e alterando o tamanho do círculo pontilhado. O LedScope erra com facilidade quando encontra uma área com interseção de cores. A iluminação do ambiente (ou o nível de brilho do monitor, caso esteja apontado para ele) também afeta a detecção de cores.

O LedScope raramente acerta quando desejamos reconhecer a cor de um texto apontando para ele. Geralmente, ele reconhece a cor do fundo do texto, 


\section{$16^{\circ}$ \\ ERGODESIGN USIHC CINAHPA}

pois esta cor ocupa maior área que o texto. Quando apontado para widgets de interface, ele consegue reconhecer a cor deles, porém elementos pequenos dificultam a detecção de cores.

O Color Blind Pal (http://colorblindpal.com/) é um aplicativo gratuito para Android, iOS e Mac. No modo Color Inspector (parte superior esquerda da Figura 7), o usuário aponta a câmera do dispositivo para um objeto e vê um nome descritivo daquela cor na tela; também permite ver detalhes como matiz, saturação e o RGB da cor. Apesar de o cruzamento das linhas ser mais preciso do que um círculo para indicar a cor que se deseja, o usuário precisa congelar a imagem para continuar movendo o dispositivo livremente.

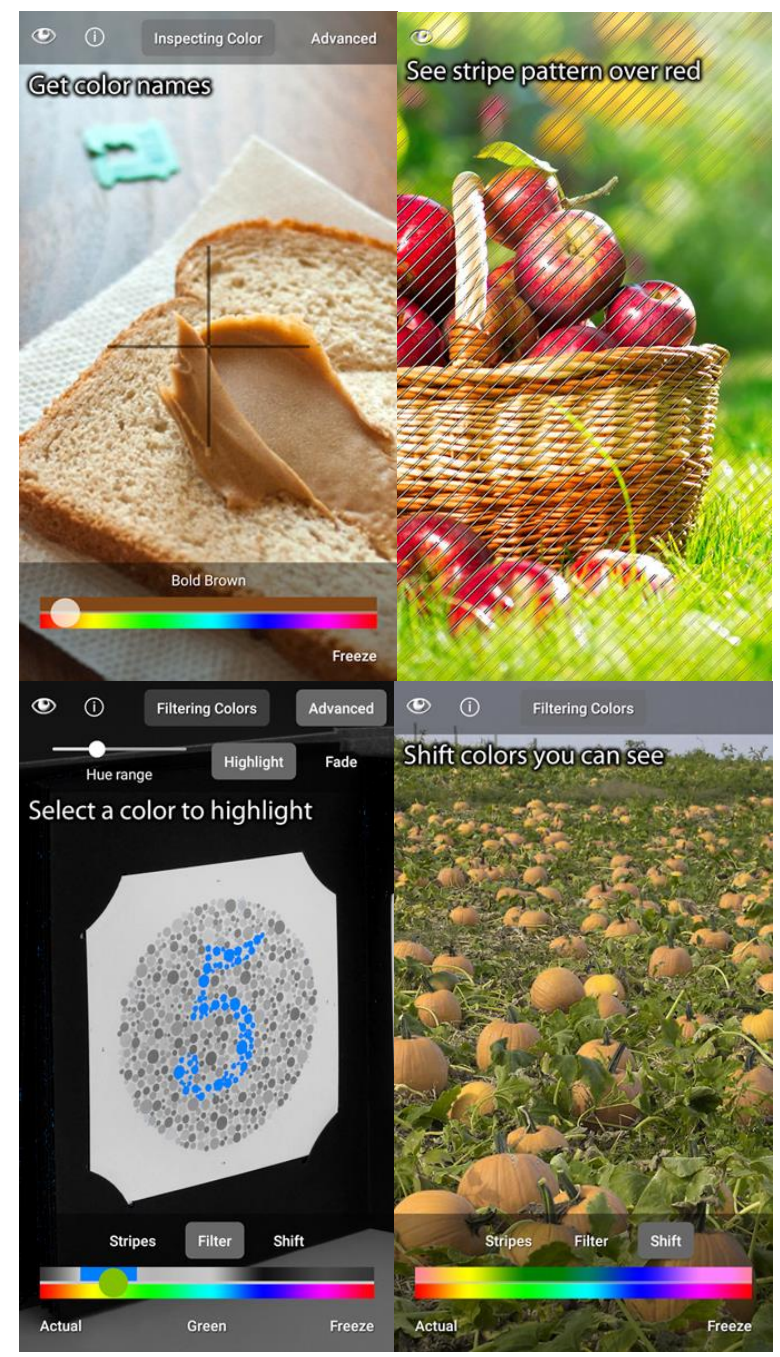

Figura 7. Aplicativo Color Blind Pal (Fonte: Play Store). $16^{\circ}$ Ergodesign - Congresso Internacional de Ergonomia e Usabilidade de Interfaces Humano Tecnológica: Produto, Informações Ambientes Construídos e Transporte

$16^{\circ}$ USIHC - Congresso Internacional de Ergonomia e Usabilidade de Interfaces Humano Computador

CINAHPA | 2017 - Congresso Internacional de Ambientes Hipermídia para Aprendizagem.

No modo Filter Color (Figura 7), é possível desenhar um padrão de listras sobre uma determinada cor na imagem (Stripes, parte superior direita), destacar uma cor específica (Filter, parte inferior esquerda), ou transformar (Shift, parte inferior direita) as cores que são difíceis de distinguir. Estes podem ser recursos interessantes para que o daltônico identifique certas cores. Se o trabalho necessário para identificar cores for aceitável e não muito recorrente, o designer pode conceber uma interface para ser utilizada em conjunto com uma tecnologia assistiva semelhante.

Outra tecnologia assistiva para sites web é fornecer uma maneira automática de explicitar para o usuário daltônico certas cores nas páginas através de CSS. Por exemplo, a ferramenta CED (http:// www.daltonicos.com.br/daltonico/) edita o arquivo CSS original para explicitar ao usuário daltônico algumas cores dos textos. Os textos coloridos recebem um fundo de destaque, acompanhado do nome da cor quando o usuário posiciona o mouse sobre o texto (Figura 8). Infelizmente, o CED não está disponível para o uso no momento, mas este princípio poderia ser explorado no futuro por outras tecnologias assistivas relevantes. Como a ferramenta foi feita utilizando uma técnica de conversão para textos, ela não possui nenhum tipo de suporte para imagens. A ferramenta também não possui nenhum suporte para conversão automática de elementos da interface.

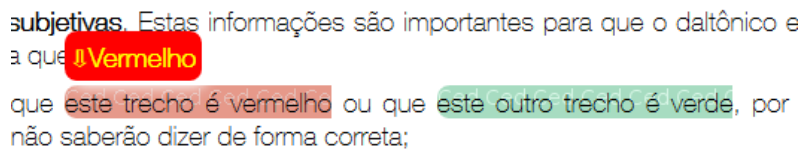

Figura 8. Exemplo do CED (fonte: site da ferramenta).

\subsection{Comparação de Tecnologias Assistivas}

Durante nossa pesquisa, encontramos muitos inspetores de cores de propósito geral que podem ajudar usuários daltônicos. Tivemos acesso a poucas tecnologias assistivas desenvolvidas especificamente para este público em nossa pesquisa no Google e lojas de aplicativos. O Color Blind Pal possui uma versão para MacOS. Nenhum outro aplicativo desktop relevante foi encontrado.
Realização:

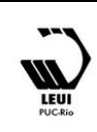




\section{$16^{\circ}$ \\ ERGODESIGN USIHC CINAHPA}

As tecnologias assistivas analisadas buscam apoiar as atividades diárias de daltônicos. A maioria busca auxiliar o daltônico a distinguir e reconhecer cores; capacidade importante para identificarmos objetos específicos, ler mapas, gráficos, legendas ou qualquer informação representada em cores. Além disso, também encontramos iniciativas específicas para identificar cores de textos. A Tabela 2 apresenta uma comparação geral das tecnologias assistivas analisadas. De todas elas, o aplicativo $16^{\circ}$ Ergodesign - Congresso Internacional de Ergonomia e Usabilidade de Interfaces Humano Tecnológica: Produto, Informações Ambientes Construídos e Transporte

$16^{\circ}$ USIHC - Congresso Internacional de Ergonomia e Usabilidade de Interfaces Humano Computador

CINAHPA | 2017 - Congresso Internacional de Ambientes Hipermídia para Aprendizagem.

Color Blind Pal se destacou pelo conjunto de funcionalidades interessantes que os outros aplicativos analisados não possuem.

Quando for difícil conceber uma boa solução de interface que não dependa da representação de informações por cores, o designer pode analisar se sua solução pode ser acessível a daltônicos sendo utilizada em conjunto com algumas dessas tecnologias assistivas.

\begin{tabular}{|c|c|c|c|}
\hline $\begin{array}{l}\text { Tecnologia } \\
\text { Assistiva }\end{array}$ & Plataforma & Pontos fortes & Pontos fracos \\
\hline LedScope & $\begin{array}{l}\text { aplicativo } \\
\text { móvel }\end{array}$ & $\begin{array}{l}\text { Representa a cor na forma de texto, em valor } \\
\text { digital e a posição na roda de cores. }\end{array}$ & $\begin{array}{l}\text { Não acerta a cor de um texto ou de áreas com interseção de } \\
\text { cores. Reconhece apenas as matizes básicas. Dificuldade em } \\
\text { detectar a cor de pequenas regiões. }\end{array}$ \\
\hline$\underline{\text { Colblindor }}$ & sistema web & $\begin{array}{l}\text { Informa o nome e matiz de uma cor a partir do } \\
\text { código RGB. Tem um grande banco de dado de } \\
\text { nomes. }\end{array}$ & $\begin{array}{l}\text { É preciso utilizar em conjuntos com outras ferramentas do } \\
\text { tipo "contas gotas" para capturar o código RGB de uma cor } \\
\text { na tela. }\end{array}$ \\
\hline$\underline{\text { Color Blind }}$ & $\begin{array}{l}\text { aplicativo } \\
\text { móvel e } \\
\text { MAC }\end{array}$ & $\begin{array}{l}\text { Utiliza a câmera para inspecionar a cor de um } \\
\text { objeto. Exibe o nome, matiz, saturação e RGB } \\
\text { da cor. Aplica filtros na imagem: desenha } \\
\text { padrões sobre regiões com determinada cor, } \\
\text { destaca uma cor (colocando as outras em preto } \\
\text { e branco) ou ajusta o contraste entre as cores } \\
\text { para ajudar o daltônico a distingui-las. Também } \\
\text { simula as dicromacias. }\end{array}$ & \\
\hline$\underline{\mathrm{CED}}$ & sistema web & Permite diferenciar textos coloridos na web. & $\begin{array}{l}\text { Não está disponível para o uso no momento. Dá suporte } \\
\text { apenas às cores primárias: vermelho, verde e azul. Outras } \\
\text { cores são marcadas como cinza. Não dá suporte para } \\
\text { imagens ou outros widgets. }\end{array}$ \\
\hline
\end{tabular}

Tabela 2. Comparação de tecnologias assistivas para daltônicos.

\section{Considerações Finais}

Este trabalho apresentou uma análise de simuladores e tecnologias assistivas para daltônicos, com o objetivo de instrumentar o trabalho de designers não daltônicos durante o projeto de interface para usuários daltônicos. Identificamos um conjunto de ferramentas computacionais que podem auxiliar a avaliação formativa e somativa das soluções sendo concebidas. Destacamos seu potencial para auxiliar a análise estática da interface e a análise dinâmica da interação sob o ponto de vista dos daltônicos.

Apesar de alguns considerarem que o desafio de projetar uma interface acessível para daltônicos pode ser resolvido com um estudo de contraste transformando todas as cores em tons de cinza [Silva, 2010], acreditamos que o estudo de simuladores e tecnologias assistivas apresentado aqui seja relevante para apoiar e facilitar o trabalho do designer de forma mais ampla e operacional.

\section{BIBLIOGRAFIA}

BARBOSA, S.D.J.; SILVA, B.S. Interação humano-computador. Rio de Janeiro: Elsevier, 2010 .

Brasil, Decreto $n^{\circ} 6.949$, de 25 de agosto de 2009. http://www.planalto.gov.br/ccivil_03/_ato20072010/2009/decreto/d6949.htm 


\section{$16^{\circ}$ \\ ERGODESIGN USIHC CINAHPA}

BRUNI, L. F.; CRUZ, A. A. V. Sentido cromático: tipos de defeitos e testes de avaliação clínica. Arq. Bras. Oftalmol., São Paulo, v. 69, n. 5, p. 766775, 2006.

FARINA, M.; PEREZ, C.; BASTOS, D.

Psicodinâmica das cores em comunicação. 5. ed. São Paulo: Edgard Blucher, 2006.

Ferraz, G.S. Dispositivo Móvel para a Percepção Cromática em Deficientes Dicromáticos.

Dissertação de Mestrado em Sistemas de Informação, Instituto Politécnico de Bragança, 2011.

GOMES, J.P.; SILVA, M.J.B.; NASCIMENTO, P.L.S.; NETO, A.J.V. "Que cor é essa? Analisando a experiência do daltônico no ambiente de loja". Métodos e Pesquisa em Administração, v. 1, n. 1, p. 45-56, 2016.

GORDON, N. Colour blindness. Public Health, v. 112, n. 2, p. 81-84, 1998.

JENNY, B.; KELSO, N.V. Designing maps for the colour-vision impaired. Bulletin of the Society of Cartographers SoC, 41, p. 9-12, 2007.

MAIA, A.F.D.V.M.; SPINILLO, C.G. Como os Daltônicos percebem as Representações Gráficas de Mapas: Um Estudo de Caso dos códigos de cores utilizados nos Diagramas e Estação-Tubo do Transporte Público de Curitiba. Design \& Tecnologia, 05, 2013.

MELO, A.M.; BARANAUSKAS, M.C.C. Design inclusivo de sistemas de informação na Web.

Anais do VII Simpósio sobre Fatores Humanos em Sistemas Computacionais, 2006.

MELO, D. G.; GALON, J. E. V.; FONTANELLA, B. J. B. Os "daltônicos" e suas dificuldades: condição negligenciada no Brasil?. Physis Revista de Saúde Coletiva, vol. 24, núm. 4, pp. 1229-1253, 2014.

NEIVA, M.; GUEDES, M.G. Color Identifying System for Color Blind People. Proceedings of 11th Congress of the International Colour $16^{\circ}$ Ergodesign - Congresso Internacional de Ergonomia e Usabilidade de Interfaces Humano Tecnológica: Produto, Informações Ambientes Construídos e Transporte

$16^{\circ}$ USIHC - Congresso Internacional de Ergonomia e Usabilidade de Interfaces Humano Computador

CINAHPA | 2017 - Congresso Internacional de Ambientes Hipermídia para Aprendizagem.

Association, 2009.

OLIVEIRA, R.F.; PUGLIESI, E.A.; RAMOS, A.P.M.; DECANINI, M.M.S. Simulador de Visão de Cores para Aplicação na Cartografia: da Visão Tricromata Normal para a Visão do Daltônico Dicromata. Anais do V Simpósio Brasileiro de Ciências Geodésicas e Tecnologias da Geoinformação, 2014.

RIBEIRO, M.M.G. ; GOMES, A. Adaptação de cor para dicromatas na visualização de imagens. Anais do Encontro Português de Computação Gráfica, 2010.

ROGERS, Y.; SHARP, H.; PREECE, J. Design de interação: além da interação humanocomputador. 3.ed. Porto Alegre: Bookman, 2013.

SOARES, R. Avaliação dos Condutores Portadores de Discomatropsia Congênita na Percepção Cromática da Sinalização Viária. Dissertação de Mestrado em Transportes, Universidade de Brasília, 2009.

SILVA, C. Design para web: Por onde andamos e para onde vamos. Arcos Design, vol.5, $n^{\circ} 2$, Dezembro 2010.

SILVA, C.; MARTINS R. Nova teoria sobre luz e cores: uma tradução comentada, Revista Brasileira de Ensino de Física, 18(4): 313-27, 1996. 